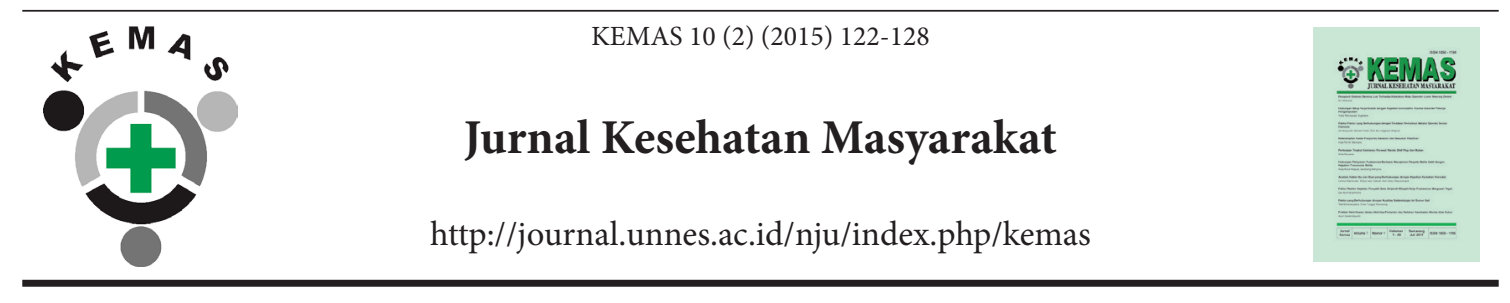

\title{
FAKTOR-FAKTOR TERJADINYA TUBERKULOSIS
}

\author{
Ardhitya Sejati ${ }^{\bowtie}$, Liena Sofiana
}

Fakultas Kesehatan Masyarakat, Universitas Ahmad Dahlan

\section{Info Artikel \\ Sejarah Artikel: \\ Diterima 2 September 2014 \\ Disetujui 25 Oktober 2014 \\ Dipublikasikan Januari}

Keywords:

Tuberculosis;

residential density;

smoking habit;

economic status.

\begin{abstract}
Abstrak
Kualitas pengobatan tuberkulosis di DIY berdasarkan laporan P2M, meskipun dari tahun ke tahun terus meningkat namun, tetap masih rendah, yaitu angka kesembuhan baru mencapai $84,07 \%$ (target $85 \%$ ). Cakupan penemuan tuberkulosis di Puskesmas Depok 3 dirasa masih rendah pada tahun 2011 terdapat 23 kasus, tahun 201219 kasus, sedangkan pada tahun 2013 terdapat 25 kasus. Penelitian ini bertujuan untuk mengetahui faktor-faktor apa saja yang berhubungan dengan kejadian tuberkulosis di Puskesmas Depok 3 Kabupaten Sleman. Jenis penelitian ini adalah analitik observasional dengan pendekatan sampel case control yang dilakukan pada tahun 2014. Sampel penelitian ini adalah 60 responden, dengan kasus sebanyak 20 responden, dan kontrol sebanyak 40 responden (perbandingan 1:2). Analisis data dengan menggunakan uji chi-square dan Fisher's exact test. Hasil menunjukkan tidak ada hubungan kepadatan hunian rumah $(p$ value 0,422 , OR 2,250), kebiasaan merokok ( $p$ value 1,000 , OR 1,000) dan status ekonomi ( $p$ value 1,000, OR 1,123) dengan tuberkulosis di Puskesmas Depok 3 Kabupaten Sleman. Kesimpulannya tidak ada hubungan kepadatan hunian, kebiasaan merokok, dan status ekonomi dengan tuberkulosis.
\end{abstract}

\section{FATORS RELATED WITH TUBERCULOSIS}

\begin{abstract}
The quality of tuberculosis treatment in the DIY province based on the report of P2M, although from year to year keep increasing but still low, the cure rate has reached 84.07\% (target of 85\%). Tubeculosis detection coverage in Depok 3 primer health centre (puskesmas) is still low, it's seen that in 2011 there were 23 cases, 19 cases in 2012, whereas in 2013 there were 25 cases. This study aims to determine what factors that have connection with the incidence of tuberculosis in Depok 3 Primer Health Care of Sleman distric. This research is an observational analytic sample case control in 2014. The study's sample were 60 respondents, with as many as 20 cases of respondents, and control as many as 40 respondents (ratio 1:2). Data analysis using chi-square test and Fisher's exact test. The result there was no relationship between the density of residential ( $p$ value $0,422, O R 2,250$ ), smoking habits ( $p$ value 1,000, OR 1,000), occupation and economic status ( $p$ value 1,000, OR 1,123) with the occurrence of tuberculosis in Depok 3 Primer Primer Health Care of Sleman distric. Conclution there was no relationship between the density of residential, smoking habits, occupation, and economic status with tuberculosis.
\end{abstract}

(C) 2015 Universitas Negeri Semarang

Alamat korespondensi:

ISSN 1858-1196

Jalan.Prof. Dr. Soepomo, SH, Janturan, Warungboto, Umbulharjo, Yogyakarta

(Kampus 3), Telp. 085292200039

E-mail: Ardhisejati@yahoo.co.id 


\section{Pendahuluan}

Perhatian aktivis sedunia dikejutkan oleh deklarasi "kedaruratan global" (the global emergency) tuberculosis pada tahun 1993 dari WHO, karena sebagian besar negara-negara di dunia tidak berhasil mengendalikan penyakit tuberkulosis. Hal ini disebabkan oleh angka kesembuhan penderita yang berdampak pada tingginya penularan. Penyakit tuberkulosis sudah ada sejak ribuan tahun sebelum masehi. Menurut hasil penelitian, penyakit tuberkulosis sudah ada sejak zaman Mesir kuno yang dibuktikan dengan penemuan pada mumi. Pada tahun 1882, ilmuwan Robert Koch berhasil menemukan kuman tuberkulosis, yang merupakan penyebab penyakit ini. Kuman ini berbentuk batang (basil) yang dikenal dengan nama "Mycobacterium tuberculosis".

Tuberkulosis merupakan penyakitkronik, menular, yang disebabkan oleh Mycobacterium tuberculosis, yang ditandai dengan jaringan granulasi nekrotik (perkijauan) sebagai respons terhadap kuman tersebut. Penyakit ini menular dengan cepat pada orang yang rentan dan daya tahan tubuh lemah. Diperkirakan seorang penderita tuberkulosis kepada 1 dari 10 orang di sekitarnya. Tuberkulosis adalah penyakit yang mengganggu sumberdaya manusia dan umumnya menyerang kelompok masyarakat dengan golongan sosial ekonomi rendah.

Indonesia memiliki beban penyakit tuberkulosis yang tinggi. Indonesia merupakan negara pertama diantara High Burden Country (HBC) di wilayah WHO South-East Asian yang mampu mencapai target global tuberkulosis untuk deteksi kasus dan keberhasilan pengobatan pada tahun 2006. Pada tahun 2009, tercatat sejumlah 294.732 kasus tuberkulosis telah ditemukan dan diobati (data awal Mei 2010) dan lebih dari 169.213 diantaranya terdeteksi BTA (+). Dengan demikian, case notification rate untuk TB BTA (+) adalah 73 per 100.000 (case detection date 73\%). Rerata pencapaian angka keberhasilan pengobatan selama 4 tahun terakhir adalah sekitar 90\% dan pada kohort tahun 2008 mencapai 91\%. Pencapaian target global tersebut merupakan tonggak pencapaian program pengendalian $\mathrm{TB}$ nasional yang utama.

Kejadian tuberkulosis dipengaruhi oleh beberapa faktor. Faktor pertama tuberkulosis adalah faktor umur karena insiden tertinggi penyakit tuberkulosis adalah pada usia dewasa muda di Indonesia diperkirakan 75\% penderita tuberkulosis adalah pada kelompok usia produktif. Faktor yang kedua adalah jenis kelamin yang lebih banyak menyerang laki-laki daripada wanita, karena sebagian besar mempunyai kebiasaan merokok. Faktor ketiga adalah kebiasaan merokok yang dapat menurunkan daya tahan tubuh, sehingga mudah untuk terserang penyakit terutama pada laki-laki yang mempunyai kebiasaan merokok (Alsagaf, 2005).

Faktor keempat adalah kepadatan hunian yang merupakan faktor lingkungan terutama pada penderita tuberkulosis yaitu kuman $M$. tuberculosis dapat masuk pada rumah yang memiliki bangunan yang gelap dan tidak ada sinar matahari yang masuk. Faktor kelima adalah pekerjaan yang merupakan faktor risiko kontak langsung dengan penderita. Risiko penularan tuberkulosis pada suatu pekerjaan adalah seorang tenaga kesehatan yang secara kontak langsung dengan pasien walaupun masih ada beberapa pekerjaan yang dapat menjadi faktor risiko yaitu seorang tenaga pabrik (Luthfi, 2012). Faktor keenam adalah status ekonomi yang merupakan faktor utama dalam keluarga masih banyak rendahnya suatu pendapatan yang rendah dapat menularkan pada penderita tuberkulosis karena pendapatan yang kecil membuat orang tidak dapat layak memenuhi syarat-syarat kesehatan (Manalu, 2010).

Berdasarkan profil kesehatan DIY, prevalensi tuberkulosis tahun 2011 sebesar 168,13 dengan angka penemuan kasus (CDR) 49,8\%, sedangkan jumlah prevalensi tahun 2012 sebesar 70,65 dengan angka penemuan kasus (CDR) 40,38\%. Terbanyak di Kabupaten Sleman sebanyak 717 kasus. Tahun 2011, di Kabupaten Sleman prevalensi penyakit tuberkulosis sebesar 45,83 dengan kasus Basil Tahan Asam (BTA) (+) 247 kasus, sedangkan pada tahun 2012 prevalensi penyakit tuberkulosis sebesar 24,13 dengan kasus BTA (+) 173 kasus. Kabupaten Sleman menempati urutan pertama dari 5 kabupaten/kota yang ada di DIY. Oleh sebab itu penyakit tuberkulosis paru di Kabupaten Sleman masih merupakan 
masalah kesehatan yang diprioritaskan oleh Dinas Kesehatan Kabupaten Sleman. Hal ini dikarenakan penyakit tuberkulosis masih ditemukan di beberapa Puskesmas. Dari semua puskesmas yang ada di Kabupaten Sleman, Puskesmas Depok 3 mempunyai penderita tuberkulosis paru yang terbanyak yaitu 25 orang. Puskesmas Depok 3 memiliki 1 wilayah kerja yang terdiri atas 20 pedukuhan.

Kualitas pengobatan tuberkulosis di Daerah Istimewa Yogyakarta (DIY) berdasarkan laporan Pemberantasan Penyakit Menular (P2M), meskipun dari tahun ke tahun terus meningkat, namun tetap masih rendah yaitu angka kesembuhan baru mencapai 84,07\% (target $85 \%$ ). Penderita tuberkulosis yang tidak sembuh atau penderita yang tidak memperoleh pengobatan karena belum ditemukan, merupakan sumber penularan yang mengancam pencapaian derajat kesehatan mengingat penyakit tuberkulosis disamping bisa menimbulkan kematian yang tinggi juga menjadi timbulnya berbagai penyakit yang fatal lain seperti HIV/AIDS, penyakit paru obstruktif, dan lain sebagainya. Sementara itu kematian dan kesakitan akibat penyakit infeksi saluran pernafasan, menjadi penyebab kematian terbesar dan memiliki kecenderungan peningkatan. Penyakit tuberkulosis memegang peran penting kasus kesakitan dan kematian penyakit saluran pernafasan tersebut dan bertanggungjawab terhadap kecenderungan peningkatannya mengingat sifat penularan dan perilaku masyarakat. Lingkup penyebab masalah penyakit tuberkulosis di Puskesmas Depok 3 ini atas beberapa faktor seperti tingkat sosial ekonomi masyarakat, tingginya tingkat kebiasaan merokok, kepadatan hunian, dan pekerjaan.

\section{Metode}

Penelitian ini merupakan penelitian studi observasional dengan menggunakan rancangan penelitian kasus kontrol. Responden dalam penelitian ini adalah orang yang melakukan pemeriksaan di Puskesmas Depok 3 dengan menggunakan tehnik total sampling yang berjumlah 20, yang didapatkan berdasarkan pemeriksaan dokter dengan uji sputum, dengan perbandingan 1:2, sehingga didapatkan
60 responden, antara sampel kasus dan sampel kontrol sampelnya dicocokkan telebih dahulu atau matching berdasarkan umur dan jenis kelamin.

Variabel penelitian ini adalah kepadatan hunian rumah, kebiasaan merokok, status ekonomi, dan kejadian tubekulosis. Alat dalam penelitian ini adalah check list. Checlist untuk mengetahui faktor-faktor terjadinya tuberkulosis di Puskesmas Depok 3 Kabupaten Sleman. Alat penelitian lain yang digunakan adalah roll meter untuk mengukur luas meter untuk mengetahui kepadatan hunian rumah.

Analisis data meliputi analisis univariat dan bivariat. Analisis univariat yaitu secara deskriptif dengan menggunakan tabel distribusi frekuensi. Analisis bivariat yaitu secara analitik untuk mengetahui hubungan antara dua variabel dengan uji chi square dan fisher's exact test untuk melihat besarnya risiko dengan odds rasio (OR).

\section{Hasil dan Pembahasan}

Hasil analisis univariat didapatkan dengan menghitung distribusi frekuensi sebaran jenis kelamin dan umur berdasarkan proses maching yang disajikan dalam tabel 1 .

Tabel 1. Distribusi Frekuensi Responden Menurut Jenis Kelamin dan Umur di Wilayah Kerja Puskesmas Depok 3 Tahun 2014

\begin{tabular}{lll}
\hline \multirow{2}{*}{ Variabel } & \multicolumn{2}{c}{ Responden } \\
\cline { 2 - 3 } & Jumlah & Persentase \\
\hline Jenis Kelamin & & \\
Laki-laki & 36 & 60 \\
Perempuan & 24 & 40 \\
Umur & & \\
$21-30$ & 21 & 35 \\
$31-40$ & 9 & 15 \\
$41-50$ & 6 & 10 \\
$51-60$ & 21 & 35 \\
$\geq 60$ & 3 & 5 \\
\hline Total & 60 & 100 \\
\hline
\end{tabular}

Sumber : data primer

Tabel 1 menunjukkan bahwa responden jumlah jenis kelamin laki-laki cenderung lebih banyak dari pada jenis kelamin perempuan 
terdiri dari 36 laki-laki dan 24 perempuan, sedangkan umur yang terbanyak berkisar pada umur 21-30 tahun dan 51-60 tahun dengan jumlah yang sama yaitu 21 responden dan yang paling sedikit berkisar antara $\geq 60$ yaitu 3 responden.

Berdasarkan hasil analisis univariat didapatkan dengan menghitung distribusi frekuensi variabel kepadatan hunian rumah, kebiasaan merokok, dan status ekonomi. Hasil analisis univariat dapat dilihat pada tabel 2 .

\section{Tabel 2. Distribusi Frekuensi Berdasarkan Karakteristik Variabel}

\begin{tabular}{lcc}
\hline \multirow{2}{*}{ Variabel } & \multicolumn{2}{c}{ Responden } \\
\cline { 2 - 3 } & $\mathbf{n}$ & $\mathbf{\%}$ \\
\hline $\begin{array}{l}\text { Kepadatan hunian } \\
\text { rumah }\end{array}$ & 8 & 13,3 \\
$\quad$ Padat & 52 & 86,6 \\
$\quad$ Tidak padat & & \\
Kebiasaan merokok & 27 & 45 \\
$\quad$ Merokok & 33 & 55 \\
$\quad$ Tidak & & \\
Status Ekonomi & 19 & 31,6 \\
$\quad$ Rendah & 41 & 68,3 \\
$\quad$ Tinggi & 60 & 100 \\
\hline Total & &
\end{tabular}

Sumber : data primer

Tabel 2 menunjukkan bahwa sebagian besar responden memiliki rumah yang tidak padatpenghuninya,sehinggakecilkemungkinan untuk terjadinya penyakit tuberkulosis.
Sebagian responden yang memiliki kebiasaan tidak merokok kemungkinan besar adalah perokok pasif. Responden yang memiliki status ekonomi rendah dapat mengurangi daya tahan tubuh seseorang menjadi lemah, sehingga mudah terserang penyakit salah satunya penyakit tuberkulosis.

Analisis bivariat merupakan analisis untuk mengetahui hubungan variabel bebas dan variabel terikat. Uji statistik yang digunakan untuk mengetahui hubungan dua variabel ini adalah uji chi square dan uji Fisher's exact test.

Berdasarkan hasil analis statistik uji Chi Square antara variabel kepadatan hunian rumah dengan terjadinya tuberculosis, kebiasaan merokok dengan terjadinya tuberkulosis, dan status ekonomi dengan terjadinya tuberkulosis menggunakan uji analisis statistik uji Chi Square dan Fisher's Square Test semuanya menunjukkan tidak adanya hubungan tuberkulosis di Puskesmas Depok 3 Kabupaten Sleman. Hal ini dapat dilihat dari nilai $p$ value $>0,05$.

Berdasarkan hasil penelitian variabel kepadatan hunian rumah memperoleh nilai $P$ value $0,422<0,05$ berarti tidak ada hubungan antara kepadatan hunian rumah dengan terjadinya tuberkulosis di Puskesmas Depok 3 Kabupaten Sleman. Tidak terbuktinya kepadatan hunian rumah dengan terjadinya tuberkulosis dikarenakan karena dari hasil observasi diperoleh data bahwa rata- rata

Tabel 3. Hasis Analisis Bivariat Antara Variabel Kepadatan Hunian Rumah, Kebiasaan Merokok, Pekerjaan, dan Status Ekonomi di Puskesmas Depok 3 Sleman Yogyakarta Tahun 2014

\begin{tabular}{|c|c|c|c|c|c|c|c|c|c|}
\hline \multirow{3}{*}{ Variabel } & \multicolumn{4}{|c|}{ Kejadian Tuberkulosis } & \multirow{2}{*}{\multicolumn{2}{|c|}{ Total }} & \multirow{3}{*}{ OR } & \multirow{3}{*}{ CI } & \multirow{3}{*}{$\begin{array}{c}P \\
\text { Value }\end{array}$} \\
\hline & \multicolumn{2}{|c|}{ Kasus } & \multicolumn{2}{|c|}{ Kontrol } & & & & & \\
\hline & $\mathbf{N}$ & $\%$ & $\mathbf{N}$ & $\%$ & $\mathbf{N}$ & $\%$ & & & \\
\hline \multicolumn{10}{|l|}{$\begin{array}{l}\text { Kepadatan hunian } \\
\text { rumah }\end{array}$} \\
\hline Padat & 4 & 20 & 4 & 10 & 8 & 13,3 & \multirow{2}{*}{2,250} & \multirow{2}{*}{$0,499-10,143$} & \multirow{2}{*}{0,422} \\
\hline Tidak Padat & 16 & 80 & 36 & 90 & 52 & 86,6 & & & \\
\hline \multicolumn{10}{|l|}{ Kebiasaan merokok } \\
\hline Merokok & 9 & 45 & 18 & 45 & 27 & 45 & \multirow{2}{*}{1,000} & \multirow{2}{*}{$0,340-2,942$} & \multirow{2}{*}{1,000} \\
\hline Tidak Merokok & 11 & 55 & 22 & 55 & 33 & 55 & & & \\
\hline \multicolumn{10}{|l|}{ Status Ekonomi } \\
\hline Tinggi & 6 & 30 & 13 & 32,5 & 19 & 31,6 & \multirow{2}{*}{1,123} & \multirow{2}{*}{$0,351-3,594$} & \multirow{2}{*}{1,000} \\
\hline Rendah & 14 & 70 & 27 & 67,5 & 41 & 68,3 & & & \\
\hline Total & 20 & 100 & 40 & 100 & 60 & 100 & & & \\
\hline
\end{tabular}

Sumber : data primer 
kepadatan hunian rumah $45 \mathrm{~m}^{2}$, hal ini masih memenuhi syarat kesehatan artinya luas rumah masih sebanding dengan jumlah penghuninya, sehingga tidak menyebabkan overcrowded dan kemungkinan kecil untuk terkena tuberkulosis.

Rumah yang cukup luas dan tidak padat, kemungkinan tidak terdapat kuman $M$. tuberculosis yang masuk ke dalam rumah. Responden yang memiliki rumah dengan padat penghuninya akan berisiko tertularnya penyakit tuberkulosis karena sirkulasi udara yang padat penghuninya berpengaruh terhadap kelembaban rumah sehingga kuman M. tuberculosis berterbangan di dalam rumah yang padat penghuninya. Sesuai dengan hasil penelitian yang menyatakan bahwa kepadatan hunian rumah bukan merupakan faktor risiko kejadian tuberkulosis paru atau tidak ada hubungan antara kepadatan hunian rumah dengan kejadian tuberkulosis paru (Fatimah, 2008). Sama halnya dengan hasil penelitian Rosiana (2013), bahwa kepadatan hunian tidak ada hubungannya dengan kejadian TB paru di wilayah kerja Puskesmas Kedungmundu Semarang, hal ini dikarenakan subjek kasus maupun pembanding mempunyai peluang yang sama untuk terpapar dan menderita $\mathrm{TB}$ paru.

Nilai OR 2,250, artinya ada kemaknaan secara biologis bahwa orang yang tinggal di rumah yang padat penghuni berisiko 2,250 kali lebih besar terkena tuberkulosis dibandingkan orang yang tinggal dirumah yang tidak padat penghuni. Penelitian lain yang dilakukan oleh Prasetyowati (2009) menunjukkan bahwa ada pengaruh kepadatan penghuni terhadap terjadinya infeksi pada TB dengan besar risiko untuk terjadinya adalah 4,653 kali dibandingkan dengan yang kepadatan penghuni yang memenuhi persyaratan.

Luas lantai bangunan rumah sehat harus cukup untuk penghuni di dalamnya, artinya luas lantai bangunan rumah tersebut harus disesuaikan dengan jumlah penghuninya agar tidak menyebabkan overload. Luas bangunan yang tidak sebanding dengan jumlah penghuninya akan menyebabkan overcrowded. Hal ini tidak sehat, sebab disamping menyebabkan kurangnya konsumsi oksigen juga bila salah satu anggota keluarga terkena penyakit infeksi, akan mudah menular kepada anggota keluarga yang lain. Persyaratan kepadatan hunian untuk seluruh rumah biasanya dinyatakan dalam $\mathrm{m}^{2} /$ orang. Luas minimum per orang sangat relatif tergantung dari kualitas bangunan dan fasilitas yang tersedia.Untuk rumah sederhana luasnya minimum $10 \mathrm{~m}^{2} /$ orang, untuk kamar tidur diperlukan luas lantai minimum $3 \mathrm{~m} 2$ /orang. Kamar tidur sebaiknya tidak dihuni lebih dari 2 orang, kecuali untuk suami isteri dan anak dibawah 2 tahun yang biasanya masih sangat memerlukan kehadiran orang tuanya. Apabila ada anggota keluarga yang menderita penyakit pernafasan sebaiknya tidak tidur sekamar dengan anggota keluarga yang lain.

Pada variabel kebiasaan merokok, memperoleh nilai $p$ value 1,000 dan CI 0,340 2,942 berarti secara statistik tidak ada hubungan antara kebiasaan merokok dengan kejadian tuberkulosis di Puskesmas Depok 3 Kabupaten Sleman. Nilai OR 1,000, artinya merokok bukan faktor risiko kejadian tuberkulosis. Hal ini dapat terjadi karena jumlah responden yang merokok lebih sedikit dibandingkan dengan responden yang tidak merokok. Hal ini disebabkan responden yang telah diteliti pernah merokok dan setelah terkena tuberkulosis responden tersebut berhenti dan tidak merokok kembali. Kondisi rumah yang sebagian besar tidak padat ini menyebabkan sulit untuk terkena keterpaparan rokok, sehingga rokok dapat menyebar dengan mudah di pemukiman tersebut. Sesuai dengan hasil penelitian yang menyatakan bahwa status kebiasaan merokok setiap hari tidak memiliki hubungan dengan kejadian tuberkulosis dewasa di Kecamatan Semarang Utara (Widyaswari, 2011).

Berbeda dengan penelitian Sarwani dan Nurlaela (2012), bahwa kebiasaan merokok berhubungan dengan kejadian TB paru $(\mathrm{p}=0,022)$. Data menyebutkan dari 34 kasus ada 17 orang diantaranya memiliki kebiasaan merokok, gambaran perilaku merokok pada kelompok kasus menunjukkan semuanya merokok lebih dari 10 batang per hari, bahkan ada hampir $40 \%$ yang merokok lebih dari 20 batang per hari. Orang yang merokok akan lebih berisiko terkena tuberkulosis disebabkan karena merokok dapat menggangu efektifitas sebagian mekanisme pertahanan respirasi. Merokok dalam rumah merupakan faKtor 
risiko untuk terkena kejadian TB paru BTA positif, polusi udara dalam ruangan dari asap rokok dapat meningkatkan risiko terinfeksi kuman M. tuberculosis.

Pada variabel status ekonomi memperoleh nilai $p$ value $1,000<0,05$ dan CI 0,351-3,594 berarti tidak ada hubungan antara status ekonomi dengan kejadian tuberkulosis di Puskesmas Depok 3 Kabupaten Sleman. Namun nilai OR 1,123, artinya orang dengan pendapatan keluarga di bawah UMR berisiko 1,123 kali lebih besar terkena tuberkulosis dibandingkan orang dengan pendapatan keluarga diatas UMR. Hal ini berarti variabel status ekonomi tidak bermakna secara statistik namun bermakna secara biologi. Hasil penelitian ini tidak sesuai dengan teori yang ada. Tidak terbuktinya variabel status ekonomi dengan terjadinya tuberkulosis di Puskesmas Depok 3 Kabupaten Sleman dikarenakan P\ pendapatan merupakan salah satu indikator untuk mengukur tingkat kesejahteraan masyarakat sebagai hasil pembangunan.

Perubahan pendapatan mempengaruhi pengeluaran. Dengan demikian, orang yang berpendapatan di bawah UMR dipandang sebagai ketidakmampuan dari sisi ekonomi untuk memenuhi kebutuhan dasar makanan dan bukan makanan yang diukur dari sisi pengeluaran. Jadi, penduduk dengan status ekonomi rendah adalah penduduk yang memiliki rata-rata pengeluaran per kapita per bulan di bawah UMR. Namun, orang yang mempunyai status ekonominya rendah mampu melakukan pengobatannya di Puskesmas Depok 3. Orang yang mempunyai ekonomi di bawah UMR, maka pemenuhan gizi berkurang dan tidak terpenuhinya gizi makanan. Hal ini menyebabkan daya tahan tubuh seseorang menjadi lemah, sehingga mudah terserang penyakit salah satunya penyakit tuberkulosis. Sesuai dengan hasil penelitian yang menyatakan bahwa tidak ada hubungan antara status ekonomi dengan kejadian tuberkulosis anak sehingga tidak masuk dalam kandidat perancu (Yulistyaningrum, 2010). Sejalan dengan hasil penelitian yang menyatakan bahwa hubungan antara tingkat ekonomi tidak bermakna atau tidak ada hubungan antara status ekonomi dengan kejadian tuberculosis (Setiarni, 2011). Berbeda dengan hasil penelitian yang dilakukan pada masyarakat di Puskesmas Purwodadi I bahwasannya bahwa ada hubungan antara pendapatan dengan kesembuhan penderita TB paru di Puskesmas Purwodadi I Kabupaten Grobogan (Murtatiningsih, 2010).

\section{Penutup}

Kesimpulan dari hasil penelitian ini dapat dikatakan ketiga faktor yaitu kepadatan hunian rumah, kebiasaan merokok dan status ekonomi secara statistic tidak ada hubungan yang signifikan dengan kejadian tuberkulosis di Puskesmas 3 Depok Kabupaten Sleman.

\section{Ucapan Terimakasih}

Ucapan terimakasih disampaikan kepada Puskesmas 3 Depok Kabupaten Sleman Yogyakarta beserta jajarannya atas keterlaksanaannya penelitian ini.Terimakasih juga diberikan kepada masyarakat di wilayah kerja Puskesmas 3 Depok Kabupaten Sleman yang menjadi sampel dalam penelitian ini.

\section{Daftar Pustaka}

Alsagafi, H; Mukty, H.A. 2005. Dasar-Sasar Ilmu Penyakit Paru, Surabaya: Airlangga University Press.

Fatimah, Siti, 2008. Faktor Kesehatan Lingkungan Rumah Yang Berhubungan Dengan Kejadian Tuberkulosis Di Kabupaten Cilacap (Kecamatan : Sidareja, Cipari, Kedungreja, Patimuan, Gandrungmangu, Bantarsari) Tahun 2008. Jurnal Keperawatan Soedirman (The Soedirman Journal of Nursing), 2 (3).

Luthfi. 2012. Tuberkulosis Nosokomial, Jurnal Tuberkulosis Indonesia, $8: 30-31$.

Manalu, Helper Sahat P. 2010. Faktor-Faktor Yang Mempengaruhi Kejadian Tuberkulosis dan Upaya Penanggulangannya, Jurnal Ekologi Kesehatan 9 (4) : 1340 - 1346.

Murtatiningsih dan Wahyono. 2010. Faktor-Faktor Yang Berhubungan Dengan Kesembuhan Penderita Tuberkulosis Paru. KEMAS 6 (1): 44-50

Prasetyowati, I dan Wahyuni, C.U. 2009. Hubungan antara Pencahayaan Rumah, Kepadatan Penguhi dan Kelembaban dan Risiko Terjadinya Infeksi TB Anak SD di Kabupaten Jember. Jurnal Kedokteran Indonesia, 1 (1) : 88-93. 
Rosiana, A.M,. 2013. Hubungan Antara Kondisi Fisik Rumah dengan Kejadian Tuberkulosis Paru. Unnes Journal of Public Health, 2 (1): 1-8.

Sarwani, D., Nurlaela, S. 2012. Merokok dan Tuberkulosis (Studi Kasus di RS Margono Soekarjo Purwokerto). Prosiding Seminar Nasional Kesehatan, Jurusan Kesehatan Masyarakat FKIK UNSOED Purwokerto.

Setiarni, Sri Marisya. 2011. Hubungan Antara Tingkat Pengetahuan, Status Ekonomi Dan Kebiasaan Merokok Dengan Kejadian Tuberkulosis Paru Pada Orang Dewasa Di Wilayah Kerja Puskesmas Tuan-Tuan
Kabupaten Ketapang Kalimantan Barat, Jurnal KESMAS, 5 :162-232.

Widyaswari, Risa Nugraheni. 2011. Hubungan Antara Jenis Kepribadian, Riwayat Diabetes Mellitus Dan Riwayat Paparan Merokok Dengan Kejadian Tuberkulosis Dewasa Di Wilayah Kecamatan Semarang Utara Tahun 2011, Jurnal Kesehatan Masyarakat, 1 (2) : $446-453$.

Yulistyaningrum. 2010. Hubungan Riwayat Kontak Penderita Tuberculosis Paru (TB) Dengan Kejadian Tuberkulosis Anak di Balai Pengobatan Penyakit Paru-Paru (BP4) Purwokerto, Jurnal KESMAS, 4 : 43-47 